\title{
O público e o privado na LDB 4.024/1961: marcos históricos para o financiamento da educação
}

The public and the private in the LDB 4.024/1961: historical frameworks for the financing of education

El público y el privado en la LDB 4.024/1961:

marcos históricos para la financiación de la educación

\author{
Rosimar Serena Siqueira Esquinsani \\ Universidade de Passo Fundo (Brasil) \\ Bolsista de Produtividade em Pesquisa do CNPq \\ https://orcid.org/0000-0002-6918-2899 \\ http://lattes.cnpq.br/9661213429808142 \\ ro.serena@hotmail.com
}

\section{Resumo}

O artigo encalça o debate educacional brasileiro no contexto dos anos 1950, na intenção de estabelecer marcos para a discussão do financiamento da educação no país. Focaliza o debate entre o público e o privado na educação, no período de elaboração da LDB 4.024/1961, bem como da interpretação dos avanços de ambas as posições no texto da lei quando de sua promulgação. Conduzido por uma metodologia analítico-reconstrutiva, o estudo consolidou-se a partir de pesquisa documental, submetida ao procedimento da análise temática. Expõe os argumentos utilizados no debate pré-LDB entre os privatistas e os defensores da escola pública; exibindo e tratando também as conquistas de ambos os projetos, incorporadas ao corpo da lei. Conclui que: a) tanto o público, quanto o privado foram beneficiados na LDB 4.024/1961, porém b) centrando o debate em pessoas e não em posicionamentos técnicos e/ou intelectuais, desviou-se o foco da questão primaz: a responsabilidade sobre o financiamento da educação.

Palavras-chave: LDB 4.024/1961. Público versus Privado. Financiamento da educação. 


\begin{abstract}
The article highlights the Brazilian educational debate in the context of the 1950s, with the intention of establishing milestones for the discussion of the financing of education in the country. It focuses on the debate between the public and private sector in education, during the period of preparation of LDB n ${ }^{\circ} 4.024$ / 1961, as well as on the interpretation of the advances of both positions in the text of the law when promulgated. Conducted by an analytical-reconstructive methodology, the study was consolidated based on documentary research, submitted to the thematic analysis procedure. It exposes the arguments used in the pre-LDB debate between privatists and public school advocates; exhibiting and treating also the achievements of both projects, incorporated into the body of law. It concludes that: (a) both the public and private sectors benefited from LDB 4,024 / 1961; (b) concentrating the debate on people rather than on technical and / or intellectual positions, the focus of the central issue: financing education. Concluye que: a) tanto el público, como el privado se beneficiaron en la LDB 4.024 / 1961, pero b) centrando el debate en personas y no en posicionamientos técnicos y / o intelectuales, se desvió el foco de la cuestión primordial: la responsabilidad sobre el financiamiento de la educación.
\end{abstract}

Key words: LDB 4.024 / 1961. Public vs Private. Education financing.

\title{
Resumen
}

El artículo persigue el debate educativo brasileño en el contexto de la década de 1950, con el propósito de establecer marcos para discutir el financiamiento de la educación en el país. El debate entre el sector público y el privado está centrado en la educación durante el período de elaboración de la LDB 4.024 / 1961, así como la interpretación de los avances de ambas posiciones en el texto de la ley cuando fue promulgada. Impulsado por una metodología analítico-reconstructiva, el estudio se consolidó a partir de la investigación documental, sometida al procedimiento de análisis temático. Expone los argumentos utilizados en el debate pre-LDB entre profesionales privados y defensores de escuelas públicas; exhibiendo y experimentando también las conquistas de ambos proyectos, incorporados al cuerpo de la ley.

Palabras clave: LDB 4.024 / 1961. Público versus Privado. Financiación de la educación. 


\section{Apresentando o tema...}

O texto assume a intenção de estabelecer marcos para a discussão e recomposição histórica acerca do financiamento da educação no Brasil, focando no debate entre o público e o privado em educação, no período de elaboração da LDB 4.024/1961, bem como da interpretação acerca dos avanços de ambas as posições no texto da lei quando de sua promulgação.

A gênese da ideia de uma lei que organizasse as "diretrizes e bases da educação nacional remonta à Constituição Federal de 1934, a primeira das nossas cartas magnas que fixou como competência privada da União 'traçar diretrizes da educação nacional' (Artigo $5^{\circ}$, Inciso XIV)" (SAVIANI, 1998, p.09), sendo que o conceito de LDB remetia a uma "lei federal sui generis [...] destinada a regular a ação dos Estados, dos Municípios, da União e da atividade particular no campo do ensino [cuja] autoridade implícita na lei sujeita a todos quanto a seu cumprimento, sua interpretação e sua execução" (TEIXEIRA, 1976, p. 227). Assim, qualquer debate em torno de uma lei com tamanha envergadura seria associado a um debate sobre projetos educativos e, em sentido amplo, sobre a sociedade em (histórica) construção.

A quinta Constituição brasileira (promulgada em 18 de setembro de 1946), conduziu os destinos do país entre 1946 e 1964. Esta Constituição informava, em seu artigo $5^{\circ}$., ser competência da União legislar sobre as diretrizes e bases da educação nacional (parágrafo $\mathrm{XV}$, alínea 'd'). De tal modo, para dar início ao cumprimento do dispositivo legal, em 1948, o Ministério da Educação e Cultura apresentou a sua proposta para a Lei de Diretrizes e Bases da Educação Nacional - o anteprojeto de Clemente Mariani (Salvador/BA, 1900 — Salvador/BA, 1981).

Nesse contexto jurídico-normativo tramitou durante treze anos, o projeto da Lei de Diretrizes e Bases da Educação Nacional que, entre idas e vindas no Congresso Nacional, passou por uma comissão mista de estudos, composta por protagonistas ligados aos mais diversos setores e tendências, desde católicos tradicionais, intelectuais escolanovistas e até mesmo antigos colaboradores do Estado Novo.

Pela inerente condição plural da comissão, a mesma foi palco - e trouxe à tona distintas discussões e posicionamentos, inclusive disputas entre os defensores da escola pública, sobretudo através do educador baiano Anísio Spínola Teixeira (Caetité/Bahia, 12 de julho de 1900 — Rio de Janeiro/Rio de Janeiro, 11 de março de 1971) e os contrários à maior intervenção do Estado no campo educacional, esses sob forte liderança da Igreja Católica.

Os debates por ocasião da elaboração daquela que seria a primeira LDB, restaram por assinalar o próprio texto da lei e, por consequência, dispor marcos em relação ao financiamento da educação brasileira, balizados ora por interesses públicos, ora pelas vitórias políticas da iniciativa privada.

Em razão da recomposição de fatos históricos, texto apresenta resultados de uma pesquisa de base documental, respaldada por uma revisão bibliográfica e pautada por uma metodologia analítico-reconstrutiva, cujo escopo incidiu sobre a discussão acerca do financiamento da educação, fomentada pelo embate ideológico por ocasião da preparação da primeira Lei de Diretrizes e Bases da Educação Nacional e que restou por deixar marcas no texto legal aprovado. Os textos foram examinados a partir da metodologia da análise de conteúdo, utilizando-se a técnica da análise temática, onde o “[...] tema é a unidade de significação que se liberta naturalmente de um texto analisado, segundo critérios relativos à teoria que serve de guia à leitura" (BARDIN, 2007, p.105).

O financiamento da educação é significado, no intento da pesquisa e do consequente texto, não apenas como "um meio de realização de uma política pública setorial, a política educacional" (MARTINS, 2010, p. 498), mas também "como uma política pública, inclusive com potencial de indução da adoção de outras políticas" (MARTINS, 2010, p. 498). Desta feita, o debate em torno do financiamento da educação reproduzido pela pesquisa não diz 
respeito apenas aos mecanismos de financiamento e aos seus protocolos de aplicação, mas, de igual maneira, aos projetos em disputa quando da discussão histórica relatada pelo texto em tela, sobretudo quando o que está em discussão é a democratização da escola pública e a garantia material - financiamento -, para que tal democratização seja pleiteada.

Harwey (2005), credita a um processo histórico regular e fortalecido em disputas internas nacionais (que se materializam como tal no final da década de 1950, início da década de 1960) a estrutura necessária para a consolidação e avanço do neoliberalismo em escala mundial. Por tal lógica, os debates travados no Brasil, por ocasião da futura LDB, são partícipes de tal movimento, colocando em relevo muito mais do que o financiamento da educação, mas a marca de projetos sociais em disputa.

Por fim, cumpre registrar que o texto apresentado faz parte dos resultados parciais de uma pesquisa que objetiva discutir o financiamento da educação brasileira, enquanto tema candente na composição da agenda educacional.

\section{Das disputas e argumentos}

O contexto de disputas e argumentos em torno do que seria garantido, via LDB, à educação nacional representava, na década de 1950, dois movimentos bem delimitados: de um lado, representava a inovação, posto que pela primeira vez era debatido um instrumento jurídico-normativo de singular envergadura e, de outro lado, garantir espaço no texto da futura lei importava, de certo modo, garantir legitimidade a projetos de sociedade específicos. Nesta direção, favoráveis ao investimento público direcionado nomeadamente à escola pública e favoráveis ao financiamento público indireto - destinando parte dos valores a serem investidos na educação também para a iniciativa privada -, engalfinhavamse em argumentos e posições políticas.

Anísio Spínola Teixeira era um intelectual de ação (e posicionamento) política. A ingerência de Teixeira no debate determinando, em contraposição, a explicitação veemente da posição da Igreja Católica - que o identificou como contendor a ser vencido -, principiou quando ele apresentou uma conferência intitulada "A Escola pública, universal e gratuita", no I Congresso Estadual de Educação Primária, ocorrido em Ribeirão Preto, São Paulo, entre os dias 16 e 23 de setembro de 1956. Nessa conferência, Anísio defendeu a escola pública, considerada por ele como a única verdadeiramente democrática, sublinhando que somente os que assim quisessem é que deveriam procurar a educação privada (TEIXEIRA, 1956).

$\mathrm{Na}$ aludida conferência, Anísio mencionou possíveis causas para os problemas educacionais de então. Em sua menção restou por atacar, de forma indireta, a escola privada, posto que dentre as causas da então situação educacional Teixeira apontava a “...relativa ausência de vigor de nossa atual concepção de escola pública e a aceitação semi-indiferente da escola particular foram e são, ao meu ver, um dos aspectos dessa desfiguração generalizada de que sofre a política educacional brasileira...” (TEIXEIRA, 1956, p. 4).

A reação da Igreja Católica, investida da autoridade de defensora da escola privada, foi desencadeada a partir de novembro do mesmo ano, quando o deputado federal padre José Trindade da Fonseca e Silva (Jaraguá/GO, 1904 - Goiânia/GO, 1962) fez um discurso no plenário da Câmara, em tom de alerta ao ministro da Educação (cargo então exercido por Clóvis Salgado da Gama) posicionando-se de maneira contrária a influência que Anísio Teixeira exercia junto ao MEC, insinuando estar o educador baiano vinculado ao comunismo e, por essa razão, ir de encontro aos interesses das escolas confessionais.

Toda a irritação de Fonseca e Silva contra Anísio Teixeira estava sendo usada pelos proprietários de escolas particulares, confessionais ou não, que se insurgiam contra atitudes e atos concretos de constrangimento à 
iniciativa privada quando esta dilapidava os cofres públicos. Anísio expressava o propósito claro e deliberado de, a partir do seu raio de atuação, não privilegiar qualquer iniciativa desse tipo no âmbito educacional, muito menos o benefício discriminativo de uma religião particular (NUNES, 2000, p. 117)

Ao acontecimento seguiu-se uma resposta do ministro favorável a Anísio e um novo discurso do deputado Fonseca e Silva, enfatizando, em 14 de dezembro de 1956 que "...o Prof. Anísio Teixeira é um autêntico intelectual marxista, visto que a sua adesão á linha marxista de educação foi enunciada na famosa conferencia lida no corrente ano em congresso de educação realizado em Ribeirão Preto" (ROCHA, 1989, p.49). As manifestações alimentaram os debates no decorrer de 1957, com o envolvimento de outros protagonistas de ambos os lados.

Em meio a contenda e tornando a situação ainda mais tensa, a portaria 1509 da Comissão Federal de Abastecimento e Preços - COFAP -, infligiu manutenção das mensalidades escolares para 1958 aos valores cobrados no exercício anterior, mexendo abertamente no 'caixa' das instituições privadas.

A COFAP era a Comissão de controle de preços do governo, criada no âmbito da Lei ${ }^{\circ}$ 1.522, de 26 de dezembro de 1951, que autorizava o Governo Federal a intervir no domínio econômico para assegurar a livre distribuição de produtos necessários ao consumo. Tal Comissão foi revogada pela Lei Delegada no. 04, de 26 de setembro de 1962, com regulamentação no Decreto ${ }^{\circ}$ 53.460, de 21 de Janeiro de 1964.

Assim o contexto potencialmente efervescente fez com que outros membros do clero viessem à público. Todavia, o pronunciamento que assinalou indelevelmente o debate, ocorreu em 29 de março de 1958, quando Dom Vicente Scherer (Bom Princípio/RS, 5 de fevereiro de 1903 - Porto Alegre/RS, 8 de março de 1996) - então arcebispo de Porto Alegre/RS -, lançou um memorial assinado por todos os bispos do estado do Rio Grande do Sul, intitulado Memorial do Bispos Gaúchos ao Presidente da República sobre a Escola Pública Única, dirigido ao então presidente Juscelino Kubitschek (Diamantina/MG, 12 de setembro de 1902 - Resende/RJ, 22 de agosto de 1976). O Memorial restou por ser o precursor de outras manifestações da Igreja. Em abril, os bispos da província de Belo Horizonte publicaram a Carta Pastoral contra o monopólio estatal e pela liberdade de ensino e, em julho do mesmo ano, três cardeais e 83 bispos, reunidos em Goiânia, manifestaram-se publicamente através da Declaração dos Cardeais, Arcebispos e Bispos do Brasil.

Os pronunciamentos públicos tinham caráter ideológico, escamoteando em defesas pastorais o que de fato estava em jogo: a materialização de projetos educacionais a serem garantidos no corpo da futura LDB e que intentavam ganhos para muito além da garantia do direito das famílias escolherem a educação dos filhos. Os discursos dos representantes católicos, por exemplo, pautavam-se no apelo à figura do bispo como o "... pastor e pai, que não conhece preocupações e alegrias outras que o bem espiritual e material das ovelhas de Cristo, confiadas à sua solicitude, à sua vigilância e ao seu governo" (SCHERER, 1958b, p. 65).

No cenário descrito, a contenda e o debate instigados pela Igreja Católica pareciam lograr êxito e enfraquecer o posicionamento dos defensores da escola pública. Praticamente um ano e meio antes da publicação da lei, Anísio Teixeira já escrevia ao deputado San Tiago Dantas, queixando-se de que estava sendo preterido na Comissão de Educação e na subcomissão que estudava o texto da futura lei. Não se abstinha, entretanto, de emitir seu parecer sobre o texto legal, ainda obscuro e equívoco pela "luta de interesses em que está se querendo envolver a escola" (TEIXEIRA, 1959). Dizia... 
Reconheço que me retraí de comparecer espontaneamente à Comissão de Educação, devido à campanha que venho sofrendo do grupo que julgou usado o momento para a conquista da escola, a fim de pô-la a serviço do que se vem chamando de "grupos sociais" e que se advinha o que seja, mas, de forma antes implícita do que explícita. (TEIXEIRA, 1959)

Ainda data de momentos anteriores à promulgação da lei, o desabafo de Anísio sobre a estreita vinculação "forçada" entre o público e o privado naquela que seria a LDB 4.024: “...parece que algo de incoercível compele o país a fazer do público o privado, ou seja, a dar ao privado as regalias e privilégios do público" (TEIXEIRA, 1960, p.16).

Da mesma forma, para o educador baiano, subsidiar com recursos públicos a iniciativa privada no campo educacional, pressuposto mantido implicitamente na LDB 4.024/61, nada mais era do que, além de fazer do público o privado, ratificar a sociedade de classes quase que estamentalmente divididas a partir de princípios não apenas financeiros, mas também de escolarização, pois “... a educação que a escola particular irá expandir terá, pois, de ser a educação chamada de 'classe', isto é, destinada a preparar os filhos dos já educados para sucedê-los em seus privilégios e direitos adquiridos" (TEIXEIRA, 1960, p.19), isto não significava, na perspectiva de Anísio Teixeira que a escola privada fosse banida do sistema de ensino, pelo contrário, "... a nossa Constituição liberalmente permite a sua existência. Mas entre isto e promovê-la, e custeá-la, vai um abismo!...” (TEIXEIRA, 1960, p.19).

Diante desse quadro ideológico, as pautas defendidas pelo educador baiano soavam como argumentos contra a ideia privatista de organizar-se sob o manto do financiamento público indireto, concorrendo com os recursos que, na visão de Anísio, deveriam ser destinados às instituições públicas exclusivamente.

A aparente incapacidade dos defensores privatistas em compreender os argumentos anisianos, dizia mais respeito ao projeto de sociedade por eles encampado, do que ao financiamento da educação em sentido estrito, uma vez que "el elemento democrático -y político- de la educación se sitúa en esa doble experiencia: en la experiencia del mundo como bien común y en la experiencia del 'yo puedo' (como opuesta a la experiencia del 'yo debo')". (SIMONS; MASSCHELEIN, 2014, p.46).

O debate público direto e nominal entre a Igreja Católica e Anísio Teixeira esfriou e deixou as páginas dos jornais em fins de 1958, quando entrou em cena outro protagonista nesta história, o deputado Carlos Lacerda (União Democrática Nacional - UDN), com seu substitutivo francamente favorável às escolas privadas, apresentado à Comissão de Educação e Cultura da Câmara Federal em 26 de novembro de 1958 (e publicado em Diário Oficial em 29 de novembro de 1958), o qual contemplava interesses dos gestores de escolas privadas, sendo um ordenamento das conclusões do III Congresso Nacional do Estabelecimentos Particulares de Ensino, realizado em 1948, dez meses antes da apresentação do anteprojeto Clemente Mariani, "pontapé” inicial da LDB.

Carlos Lacerda defendia uma orientação que era da Igreja, de que o ensino devia ser particular. Quer dizer, democraticamente, a educação só se poderia realizar através dos particulares e não através do poder público, que teria uma tendência a colocar a administração a seus serviços etc. O que se pretendia era o sistema da Holanda, em que o governo dá dinheiro para as escolas particulares realizarem o ensino, inclusive gratuito, para toda a população" (MONTEIRO, 2007, p. 148). 
O substitutivo Lacerda opunha-se ao que chamava de 'velha ideia' de um "monopólio de ensino pelo Estado, fazendo da família mera colaboradora dele, em vez de ser o Estado o supridor de recursos para que a família realize a obra educacional" (DIÁRIO, 1958, p. 7626)

Nesta direção, um dos trechos do substitutivo, exemplarmente, aponta ser: "vedado ao Estado exercer ou de qualquer modo favorecer o monopólio do ensino, assegurado o direito paterno de prover, com prioridade absoluta a educação dos filhos e o dos particulares comunicarem aos outros os seus conhecimentos" (DIÁRIO, 1958, p. 7622). Assim, a grande bandeira do substitutivo se desfraldava ante ao direito da família em relação a educação dos filhos.

Perante o teor do substitutivo, Anísio Teixeira também reconhecia o avanço privatista e expressava seu desconforto: "como vê meu caro San Tiago Dantas, a lei ainda ficou, a despeito de seu esforço, marcada pelo espírito dos interesses que presidiram a elaboração do absurdo substitutivo - Lacerda" (TEIXEIRA, 1959).

Com tamanha ênfase na lógica privatista - contrapondo os interesses de donos e gestores de escolas privadas ao projeto de escola pública -, o anunciado substitutivo restou por desencadear o Manifesto dos Educadores novamente Convocados, em julho de 1959, além da Campanha Nacional de Defesa da Escola Pública, caracterizada por uma série de eventos (notadamente a publicação de artigos e editoriais), de dezembro de 1958 até a aprovação da redação final da LDB, em 22 de janeiro de 1960. Faziam parte da Campanha, além do próprio Anísio Teixeira, nomes como: Carneiro Leão, Fernando de Azevedo, Fernando Henrique Cardoso, Júlio de Mesquita Filho, Cecília Meireles, Lourenço Filho, Roque Spencer Maciel de Barros, Darcy Ribeiro, Florestan Fernandes e Miguel Reale, entre outros.

O escopo democrático de Anísio e de todos os signatários da Campanha emparelhavase às defesas mais republicanas da escola pública, reconhecendo que

muchos de los alegatos contra la escuela están motivados por un antiquísimo temor (e incluso por el odio) a una de sus características más radicales pero que la definen esencialmente: que la escuela ofrece «tiempo libre», que transforma los conocimientos y destrezas en «bienes comunes»y, por lo tanto, que tiene el potencial para proporcionar a cada cual, independientemente de sus antecedentes, de su aptitud o de su talento natural, el tiempo y el espacio para abandonar su entorno conocido, para alzarse sobre sí mismo y para renovar el mundo (para cambiarlo de un modo impredecible) (SIMONS; MASSCHELEIN, 2014, p.03).

Depois de tantos e tão intensos interesses e movimentos o clero, por fim, saiu do debate. Havia deixado sua contribuição aos rumos que tomaria a futura Lei de Diretrizes e Bases da Educação Nacional e, consequentemente, o financiamento da educação brasileira após tal lei. Anísio estava combalido, senão pelo desgaste de seus argumentos, pela excessiva exposição à opinião pública, e o recado estava dado: era preciso garantir espaços e aportes financeiros legais para a escola privada a fim de garantir a liberdade de escolha dos pais da escola para seus filhos, o que vinha ao encontro da “...tradição cristã do povo brasileiro" (SCHERER, 1958a).

\section{Meia vitória... mas vitória...}

Após pronto e homologado o texto da LDB 4.024/61, é possível identificar incontestes dos interesses privatistas no campo educacional, em detrimento da própria educação pública. Entretanto, Anísio em seu “...incurável otimismo, disse que a LDB era uma meia vitória... mas uma vitória" (CUNHA; GÓES, 1996, p.14). Esta mesma expressão serviu de título para um artigo que Anísio publicou no ano seguinte, na Revista Brasileira de Estudos Pedagógicos. Em 
tal artigo, o autor disserta sobre a recém-aprovada Lei de Diretrizes e Base da Educação Nacional, admitindo que referida lei estava muito aquém das circunstâncias sociais em que se encontrava o Brasil, mas, ainda assim, concedia certos benefícios e alinhavos para o ensino no país.

No que concerne especificamente ao tema financiamento, é possível verificar aqui a materialização de "uma ambiguidade ou hibridismo das políticas públicas de financiamento da educação: são determinadas pelas políticas educacionais ao mesmo tempo em que são determinantes" (MARTINS, 2010, p.499), pois, ao mesmo tempo que o tema pautou a discussão circunscrita a percentuais, valores e repasses, também balizou uma discussão de projeto social mais amplo, ancorando e ampliando a discussão aparentemente simplista da destinação de verbas, vinculando tal discussão ao debate sobre a legitimação de diferentes projetos educacionais: defesa da escola pública $\mathrm{X}$ perspectiva privatista.

Tomando como objeto de análise o texto da LDB 4.024/1961, é possível verificar o quão a querela foi, ideologicamente, vencida pelos argumentos privatistas amparados pelo apoio e apelo católico. Já no TÍTULO II - Do Direito à Educação, o Art. $2^{\circ}$ deixa claro que "A educação é direito de todos e será dada no lar e na escola" (BRASIL, 1961), condição reforçada pelo parágrafo único do mesmo artigo, que institui: "à família cabe escolher o gênero de educação que deve dar a seus filhos” (BRASIL, 1961).

Assim, sobressai-se a primazia da família em relação a educação, o que causa efeitos amplamente favoráveis ao grupo privatista, pois se a família é prioritária no processo educativo, a presença do Estado neste campo é periférica e subsidiária, impossibilitando um projeto de educação nacional e sistemático (que passaria, obrigatoriamente, pela escola pública) e favorecendo o fortalecimento de instituições vinculadas a iniciativa privada. O Art. $3^{\circ}$ é ainda mais enfático ao assumir que o direito à educação é assegurado:

I - pela obrigação do poder público e pela liberdade de iniciativa particular de ministrarem o ensino em todos os graus, na forma de lei em vigor

II - pela obrigação do Estado de fornecer recursos indispensáveis para que a família e, na falta desta, os demais membros da sociedade se desobriguem dos encargos da educação, quando provada a insuficiência de meios, de modo que sejam asseguradas iguais oportunidades a todos (BRASIL, 1961, grifos meus).

Ora vejamos, ao Estado cabe fornecer os recursos indispensáveis para que a família se desobrigue dos encargos educacionais. Tal inciso claramente incentiva e incrementa o financiamento público indireto, no momento em que abre a possibilidade da família recorrer ao estado para que lhe seja provida a educação porém, não necessariamente em escolas públicas.

Esse artigo, ainda, restou por acobertar políticas educacionais que favoreciam a expansão das escolas particulares sob o pretexto de essas oferecerem o ensino que o Estado não podia assegurar, isso tudo em detrimento da própria rede pública e respaldado, ainda, pelo direito inalienável de a família escolher a educação para os fillhos, bandeira católica no debate preparatório à LDB e vitória garantida já no segundo artigo dessa, na qual fica claro que "à família cabe escolher o gênero de educação que deve dar a seus filhos".

Há ainda, no corpo da LDB 4.024, outras 'vitórias' dos privatistas, como no Art. 5’, que mencionava textualmente: "São assegurados aos estabelecimentos de ensino públicos e particulares legalmente autorizados, adequada representação nos conselhos estaduais de educação, e o reconhecimento, para todos os fins, dos estudos nêles realizados." (BRASIL, 1961), premissa reafirmada pelo Art. $8^{\circ}$, no que tange a representação política das escolas privadas, sendo que "na escolha dos membros do Conselho, o Presidente da República levará em consideração a necessidade de nêles serem devidamente representadas às diversas 
regiões do País, os diversos graus do ensino e o magistério oficial e particular" (BRASIL, 1961), bem como no Art 19, que especifica a equivalência de estudos em instituições públicas e privadas, na medida em que proclama: "não haverá distinção de direitos, entre os estudos realizados em estabelecimentos oficiais e os realizados em estabelecimentos particulares reconhecidos" (BRASIL, 1961)

Tal vitória privatista reverbera ainda (e principalmente) no item 'financiamento' em, pelo menos, três artigos no corpo da Lei 4.024/1961, todos no TÍTULO XII - Dos Recursos para a Educação. O primeiro dos artigos é o Art. 93, que menciona textualmente: "Os recursos a que se refere o art. 169, da Constituição Federal, serão aplicados preferencialmente na manutenção e desenvolvimento do sistema público de ensino" (Brasil, 1961, grifo meu). Mais adiante, ainda no Art. 93, o $\S 1^{\circ}$ informa que "São consideradas despesas com o ensino [...] b) as de concessão de bôlsas de estudos", caracterizando claramente o financiamento público indireto à iniciativa privada.

O segundo é o Art. 94, que versa sobre bolsas de estudos com recursos públicos, para "educandos que demonstrem necessidade e aptidão para estudos" (Brasil, 1961). Na mesma linha, o terceiro artigo que assinala o avanço privatista é o Art. 95, que fala sobre cooperação financeira. Textualmente o referido artigo indica que:

Art. 95. A União dispensará a sua cooperação financeira ao ensino sob a forma de:

a) subvenção, de acordo com as leis especiais em vigor;

[...]

c) financiamento a estabelecimentos mantidos pelos Estados, municípios ou particulares, para a compra, construção ou reforma de prédios escolares e respectivas instalações e equipamentos de acordo com as leis especiais em vigor (Brasil, 1961).

Há entretanto - e em termos específicos do financiamento da educação -, um avanço palpável na LDB de 1961, pois a mesma ratifica e amplia a vinculação de recursos para a educação, já prevista na Constituição de 1946. A Carta Magna de 1946 recupera a vinculação de recursos instituída pela Constituição de 1934 - mas retirada da Constituição de 1937 estabelecendo alíquotas de vinculação de recursos para a educação, nos seguintes percentuais e nas seguintes esferas: $10 \%$ para a União; $20 \%$ para Estados e o Distrito Federal e 20\% para os municípios. A LDB 4.024/1961 reafirma tal vinculação (Título XII, Art. 92) e amplia a alíquota da União para 12\% (PINTO; ADRIÃO, 2006).

No mesmo Art. 92 ainda encontramos três singularidades que se materializam em avanços para o financiamento da educação nacional: 1) a criação de fundos específicos de financiamento para cada nível de ensino, ou seja: o Fundo Nacional do Ensino Primário, o Fundo Nacional do Ensino Médio e o Fundo Nacional do Ensino Superior; b) a participação da sociedade civil e educacional - através do Conselho Federal de Educação - no planejamento dos investimentos de cada um desses fundos e, c) a previsão de sansões caso a alíquota mínima de investimentos na manutenção e desenvolvimento do ensino não fosse cumprida:

Art. 92. A União aplicará anualmente, na manutenção e desenvolvimento do ensino, $12 \%$ (doze por cento), no mínimo de sua receita de impostos e os Estados, o Distrito Federal e os Municípios, $20 \%$ (vinte por cento), no mínimo.

$\S 1^{\circ}$ Com nove décimos dos recursos federais destinados à educação, serão constituídos, em parcelas iguais, o Fundo Nacional do Ensino 
Primário, o Fundo Nacional do Ensino Médio e o Fundo Nacional do Ensino Superior.

$\S 2^{\circ} \mathrm{O}$ Conselho Federal de Educação elaborará, para execução em prazo determinado, o Plano de Educação referente a cada Fundo.

$\S 3^{\circ}$ Os Estados, o Distrito Federal e os municípios, se deixarem de aplicar a percentagem prevista na Constituição Federal para a manutenção e desenvolvimento do ensino, não poderão solicitar auxílio da União para esse fim (BRASIL, 1961).

No balanço final ambos os lados ganharam e ambos também perderam. Saviani (1996) por exemplo, ao historiar a LDB 4.024/1961, pontua que a lei aprovada caracterizou-se como uma solução intermediária - talvez deliberadamente conciliatória - entre os extremos do debate: o projeto original e o substitutivo do Deputado Carlos Lacerda (Vassouras/RJ, 30 de abril de 1914 - Rio de Janeiro/RJ, 21 de maio de 1977):

Portanto o texto aprovado não correspondeu plenamente às expectativas de nenhuma das partes envolvidas no processo. Foi, antes, uma solução de compromisso, uma resultante de concessões mútuas prevalecendo, portanto a estratégia da conciliação. Daí porque não deixou de haver também aqueles que consideraram a lei então aprovada pelo Congresso Nacional como inócua, tão inócua como o eram as críticas estribadas na estratégia do "liberalismo" (SAVIANI, 1996, p.47).

Em seu otimismo, Anísio mencionava que a LDB recém-promulgada era um “...documento contraditório, marcado ainda por evidente espírito privatista e sem a unidade profunda que facilitaria a implantação sempre retardada do Estado moderno e democrático em nossa terra [porém] constitui, a despeito de tudo, a primeira reforma de base na estrutura legal do país...” (TEIXEIRA, 1963, p 20). Segue afirmando que “...muitos dos seus artigos são renovadores, o seu espírito é de moderada descentralização e os dispositivos sobre o financiamento da educação abrem as portas para um plano sinérgico de esforços federais, estaduais e municipais em matéria de educação" (TEIXEIRA, 1963, p 20).

Quiçá o título 'meia vitória, mas vitória' reflita parte da decepção de Anísio Teixeira com o texto legal aprovado, mas certamente revela o paradoxo, a incongruência que foi para os defensores da escola pública, discutir pela primeira vez aquilo que se constituía em uma vitória aclamada por eles de longa data: uma lei que regulamentasse o ensino no país e, ao mesmo tempo, estabelecesse a discussão entre grupos permeados por interesses claramente privatistas, o financiamento da educação, o papel do Estado e o lugar da escola pública. E foi assim, contabilizando vitórias e derrotas, que se estabeleceu a LDB 4.024 de 1961.

\section{Por uma síntese provisória...}

Outros momentos e contextos recentes já haviam servido de palco e cenário para o debate entre o público e o privado na educação (HIRTT, 2003, VIÑAO FRAGO, 2014). Portanto, a pauta é histórica e remissiva, sobretudo quando está em jogo o financiamento da educação (HIRTT, 2003) e o consequente enfraquecimento ou mesmo desmantelamento da escola pública (VIÑAO FRAGO, 2014). Metaforicamente, o privado sempre espreitou o público, à espera de oportunidades conjunturais para colocar-se como possibilidade de qualidade educacional sem, contudo, abrir mão do financiamento estatal.

No Brasil, a década de 1950 foi um momento histórico e conjuntural propício para o debate de posições ideológicas ligadas a projetos de educação nacional. As discussões geradas 
ao longo de anos em torno da redação final da futura Lei de Diretrizes e Bases da educação nacional, colocaram em situações-limite e lados opostos defensores da escola pública e aqueles que desejavam uma maior pauta para a escola privada, delineando um momento ideologicamente rico para o debate sobre o financiamento público e o papel do setor privado na educação brasileira. Desta feita, em uma lei bastante econômica no assunto 'financiamento', os bastidores e a disputa entre o público e o privado restaram por protagonizar os maiores registros e reflexões sobre a feitura da lei e as garantias no texto da mesma.

Todavia, não era apropriado para a Igreja a discussão de políticas de financiamento da educação, pois tratar tal questão era localizar a escola confessional como escola particular. Dessa forma, o foco do debate foi oportunamente deslocado de ideias para pessoas. O foco saiu do mérito da questão do financiamento da educação e centrou-se, propositalmente, na discussão de pessoas que exerciam cargos de direção na educação nacional, como Anísio Teixeira e seu suposto envolvimento com a doutrina comunista, fundamentada no materialismo, que possivelmente se opunha à doutrina sobre a família brasileira, defendida ferrenhamente pela Igreja Católica. Ou seja, quem não estava dogmaticamente associado ao pensamento da Igreja, estaria (em tese) contra ela!

Anísio Teixeira - chamado para o debate através de declarações de representantes do clero católico desde 1957 -, posicionava-se defendendo o direito da família escolher autonomamente a escola/educação para seus filhos, desde que pudesse fazer tal escolha pautada, também de maneira autônoma, em seus próprios recursos financeiros. Os argumentos de Scherer denunciavam a suposta laicização da escola pública, logo o descomprometimento com os valores cristãos, argumento de peso em um país de forte tradição católica.

Anísio reiterava que não tinha nada especificamente contra as escolas particulares, considerando importante que elas coexistissem com escolas públicas (ele mesmo havia estudado em escola particular), desde que se mantivessem com recursos próprios. Para Anísio, a questão residia na fonte de recursos: acreditava ele que a escola privada deveria gerenciar-se com recursos privados, e não buscar o status de pública, recebendo verbas do Estado.

Enquanto a Igreja Católica - representando também o posicionamento privatista -, conseguia movimentar o país para atacar nominalmente Anísio Teixeira, questões de fundo ficavam de fora da pauta de discussões. Dessa maneira, o substitutivo Lacerda passava à opinião pública não como um agravo ao direito à educação, mas como uma 'consequência natural' da disputa ideológica em tela, isto porque centrando o debate em pessoas e não em posicionamentos técnicos e/ou intelectuais, desviou-se o foco da questão primaz: a responsabilidade sobre o financiamento da educação.

O que restou materialmente de tal contenda foi uma lei que, para Anísio, assumia feições de 'meia vitória' pois em face ao pouco arrojo da mesma ante questões como financiamento da educação, não se podia dizer que a mesma se consubstanciava em "uma lei à altura das circunstâncias em que se acha[va] o país, em uma evolução para constituir-se a grande nação moderna que todos esperamos" (TEIXEIRA, 1962, p.222).

Entretanto, se a LDB 4.024/1961 não foi a plena conquista legal de garantias do financiamento público para a educação pública, também não foi a vitória inconteste das soluções privatistas para a educação nacional. De qualquer forma, um dos marcos históricos mais relevantes da educação da nossa primeira LDB, no campo do financiamento, parece ter sido a exposição pública do tema, antes reservado às salas ministeriais, ao congresso e ao púlpito (vide forte presença da Igreja Católica no debate que precedeu a feitura da LDB), mas a partir deste marco, ampliada a um certo debate público. 


\section{Referências}

BARDIN, Laurence. Análise de Conteúdo. Trad. Luiz Antero Reto e Augusto Pinheiro. Lisboa: Edições 7, 2007.

BRASIL. Presidência da República. Casa Civil. Subchefia para Assuntos Jurídicos. Lei 4.024, de 20 de dezembro de 1961. Fixa as Diretrizes e Bases da Educação Nacional. Disponível em: http://www.planalto.gov.br/CCIVIL_03/leis/L4024.htm. Acesso em 30/03/2018.

CUNHA, Luiz Antônio; GÓES, Moacyr de. O golpe na educação. 9.ed. Rio de Janeiro: Jorge Zahar, 1996.

DIÁRIO do Congresso Nacional. Substitutivo ao projeto no. 2.222/A 1957. Fixa as Diretrizes e Bases da Educação. In., 29/11/1958. Disponível em: http://imagem.camara.gov.br/dc_20b.asp?selCodColecaoCsv=D\&Datain=29/11/1958. Acesso em 01/10/2018.

HARVEY, David. A Brief History of neoliberalism. Oxford, Oxford University Press, 2005.

HIRTT, Nico. Los nuevos amos de la Escuela. El negocio de la enseñanza. Pozuelo de Alarcón (Madrid): Minor Network, 2003.

MARTINS, Paulo de Sena. O financiamento da educação básica como política pública. RBPAE, v. 26, n. 3, set./dez, p. 497-514, 2010.

MONTEIRO, Norma de Góis (Org.) O Brasil de Clóvis Salgado. Belo Horizonte: Museu Histórico Abílio Barreto, 2007

NUNES, Clarice. Anísio Teixeira: a luta pela escola primária pública no país. In: SMOLKA, Ana Luiza Bustamante; MENEZES, Maria Cristina (Coord.). Anísio Teixeira: 1900 - 2000: provocações em educação. Campinas: Autores Associados. pp. 107-128, 2000. (Memória da educação).

PINTO, José Marcelino de Rezende; ADRIÃO, Theresa. Noções Gerais sobre o financiamento da educação no Brasil. EccoS - Revista Científica. São Paulo/SP. Vol. 8, no. 1, pp. 23-46, janjun. 2006. https://doi.org/10.5585/eccos.v8i1.457

ROCHA, João Augusto de Lima. Igreja versus Anísio Teixeira. Cadernos do IAT n. 2, Salvador: Instituto de Estudos e Pesquisas em Educação Anísio Teixeira - IAT, 1989 (Série Memória da Educação)

SAVIANI, Dermeval. Política e Educação no Brasil: O papel do Congresso na Legislação do ensino. $3^{\circ}$ ed. Campinas (SP): Autores Associados, 1996.

SAVIANI, Dermeval. A nova lei da educação: trajetória, limites e perspectivas. $4^{\mathrm{a}}$ Ed. Campinas, SP: Autores Associados, 1998. (Coleção educação contemporânea).

SCHERER, Vicente. Memorial dos bispos gaúchos ao Presidente da República sobre a Escola Pública Única. Petrópolis: Vozes - v.52 - maio 1958. p.362-364. 1958a 
SCHERER, Vicente. Discurso do senhor Arcebispo metropolitano por ocasião do seu $11^{\circ}$ aniversário de sagração episcopal. Revista Veritas, ano III - março, $\mathrm{n}^{0}$ 01. Porto Alegre: Pontifícia Univesidade Católica do Rio Grande do Sul. 1958b

SIMONS, Maarten y MASSCHELEIN, Jan. Defensa de la escuela. Una cuestión pública. Buenos Aires: Miño y Dávila, 2014.

TEIXEIRA, Anísio. A escola pública universal e gratuita. Revista Brasileira de Estudos Pedagógicos. Rio de Janeiro, v.26, n.64, out./dez. 1956. p.3-27. 1956

TEIXEIRA, Anísio. Escola pública não é invenção do socialismo nem do comunismo. O Globo, Rio de Janeiro, 27.fev. 1958a

TEIXEIRA, Anísio. Falando francamente. Entrevista. Programa de TV. 1958. Debatedor: ARNALDO NOGUEIRA. Disponível em: http://www.prossiga.br/anisioteixeira/. Acesso em $18 / 10 / 2015$. 1958 b

TEIXEIRA, Anísio. Sou contra, sou a favor. Jornal Diário de Notícias, Porto Alegre, 16.abr. 1958. 1958c

TEIXEIRA, Anísio. Nenhuma hostilidade do Inep contra escolas particulares (Entrevista). Diário da Noite, Rio de Janeiro, 21 de abril de 1958. Disponível em: http://www.prossiga.br/anisioteixeira/. Acesso em 18/10/2017. 1958d

TEIXEIRA, Anísio. Carta a San Tiago Dantas. Rio de Janeiro, 21 de julho de 1959. Localização do documento: Fundação Getúlio Vargas/CPDOC - Arquivo Anísio Teixeira (Atc 32.04.22/3). 1959 Disponível em: http://www.prossiga.br/anisioteixeira/. Acesso em 02/10/2018.

TEIXEIRA, Anísio. Meia vitória, mas vitória. Revista Brasileira de Estudos Pedagógicos. Rio de Janeiro, v.37, n.86, abr./jun. p.222-223. 1962

TEIXEIRA, Anísio. Estado atual da educação. Revista Brasileira de Estudos Pedagógicos. Rio de Janeiro, v.39, n.89, jan./mar. 1963. p.8-16.

TEIXEIRA, Anísio. Educação no Brasil. São Paulo: Companhia Editora Nacional. 1976

VIÑAO FRAG0, Antonio. Escuela pública, escuela privada. Cuadernos de pedagogía, n.451, 2014, pp 24-27.

\section{Fontes}

JORNAL Correio do Povo, Porto Alegre/ RS, ano de 1958.

JORNAL Diário de Notícias, Porto Alegre/ RS, ano de 1958.

REVISTA Brasileira de Estudos Pedagógicos, anos de 1955 a 1960.

SITE: http://www.prossiga.br/anisioteixeira/, organizado pelo Cnpq.

UNITAS - Boletim da Arquidiocese de Porto Alegre - Anos XLVI e XLVII. Porto Alegre: Cúria Metropolitana, 1957 e 1958.

VERITAS - Revista - Porto Alegre: PUCRS, 1957, 1958 e 1959. 